\title{
«МЕСТО ПОД СОЛНЦЕМ»: УРОВНИ ФОРМИРОВАНИЯ ШКОЛЬНОЙ ИНКЛЮЗИИ
}

Приоритетным направлением социальной политики развитых стран выступает активное вовлечение людей с инвалидностью в жизнь общества, в том числе в образовательный процесс. Трансформация государственной политики сопровождается внедрением и изменением нормативно-правовой базы, гарантирующей гражданские права людей с инвалидностью в различных сферах общественной жизни. В свою очередь реформы постепенно способствуют преодолению предрассудков со стороны общества к людям с инвалидностью, распространению практик взаимопомощи среди населения в реальной жизни. В сфере образовательной политики происходят преобразования, связанные с поворотом в направлении инклюзии. Формирование инклюзивной организационной культуры школ становится не менее важным условием обеспечения доступной среды, чем устранение архитектурных и технологических барьеров. Статья посвящена анализу основных ценностносимволических характеристик школьной инклюзии по материалам качественных интервью с учителями, учащимися и родителями. Эмпирическая база исследования состоит из полуструктурированных интервью с родителями, учениками, учителями, сотрудниками общеобразовательных школ, где обучаются дети с ограниченными возможностями здоровья и инвалидностью. В основе исследования концепция организационной культуры Эдгара Шейна, позволившая рассмотреть инклюзию на трех уровнях: артефактов, провозглашенных ценностей и базовых представлений. Анализ организационной культуры инклюзивных школ показал, что изменения на ценностном уровне транслируются от лидера другим участникам образовательного процесса, воплощаясь в наблюдаемых артефактах, практиках взаимодействия и непроговариваемых убеждениях.

Александра Романовна Горяйнова- аспирант, факультет социальных наук; стажер-исследователь, Центр анализа доходов и уровня жизни, Институт социальной политики, Национальный исследовательский университет «Высшая школа экономики», Москва, Россия. Электронная почта: agoryajnova@hse.ru 
На культуру организации влияют и предпринимаемые инициативы «снизу», через паттерны поведения, провозглашаемые ценности и визуальные элементы поверхностного уровня культуры. Складываясь в процессе повседневного взаимодействия, организационные ценности, нормы и установки могут способствовать, а могут выступать барьером на пути преобразований. Разделяемые ценности связаны с принятием различий, индивидуальности каждого ученика в контексте солидарности органического типа, сплоченной и поддерживающей среды.

Ключевые слова: инклюзивное образование, ученики с инвалидностью, организационная культура, социальная инклюзия, качественные методы

DOI: 10.17323/727-0634-2019-17-4-555-570

В основу концепций социальной политики многих стран мира, включая Россию, заложена идея о важности инклюзии для развития социума (см.: Ярская-Смирнова и др. 2015). О приоритетности такого вектора развития российского образования неоднократно говорилось в официальных документах, начиная с 1990-х гг. Ратификация Конвенции ООН о правах инвалидов в России в 2012 г. стала решающим шагом в этом курсе реформ (Федеральный закон 2012а). Вступивший в силу 1.01.2014 г. Федеральный Закон «Об образовании в Российской Федерации» закрепил определение инклюзивного образования (Федеральный закон 2012b), при этом, в соответствии с вступившим в силу с 1.09.2016 г. Федеральным образовательным стандартом начального общего образования обучающихся с ОВ3 (Приказ Министерства образования и науки РФ 2014), школы обязаны создать специальные образовательные условия, чтобы в них могли обучаться дети с особыми образовательными потребностями.

В 2016 г. доля детей-инвалидов среди всех детей, обучающихся в общеобразовательных организациях, составляла 1,3\% (КОУЖ 2016). В некоторых школах доля детей с инвалидностью и ОВ3 (ограниченные возможности здоровья) может достигать $10 \%$. Это так называемые инклюзивные школы: по официальным данным, в 2017 г. 21 \% школ и 16\% детских садов могли «обеспечить совместное обучение детей с особыми образовательными потребностями со сверстниками в инклюзивном формате» (РИА Новости 2017). Школы-пионеры инклюзии появились в России в начале 1990-х гг., став центрами по распространению знаний и лучших практик, ресурсом для других школ.

В связи с этим возникают вопросы о том, как формируется инклюзивная среда и особая культура в школах, где обучаются дети с инвалидностью, как административные решения отражаются на взаимоотношениях в классе и школе в целом. Вначале мы представим обзор исследований инклюзии, затем фокус будет перемещен на используемую в статье методологию изучения организационной культуры в инклюзивных образовательных учрежде- 
ниях. Далее остановимся на результатах анализа глубинных интервью об основных особенностях организационной культуры инклюзивных школ, в том числе сфокусируемся на наблюдаемых артефактах инклюзии, проанализируем представленные в нарративах убеждения информантов о ценностях равенства, разнообразия, разделяемых участниками идей инклюзии, установок по отношению к детям с особенностями развития, а также раскроем, как распространяются ценности инклюзивного образования. Данные интервью контекстуализированы с помощью данных массового опроса.

\section{Инклюзивные школы в фокусе исследований}

Зарубежные исследователи инклюзивного образования делают акцент на изучении опыта взаимодействия родителей со школьной системой (Dyson 2010), на выявлении барьеров, с которыми сталкиваются дети с особенностями развития и их родители (Resch et al. 2010; Pivik et al. 2002). Исследования инклюзивных школ проводятся во многих странах, фокусируясь на экономических, педагогических, социальных аспектах инклюзии (Ruijs, Peetsma 2009). В Украине поднимают вопрос об участии сообществ родителей в управлении школьной инклюзией (Здрагат 2017). Серия кейс-стади по исследованию инициатив в области инклюзивного образования в странах Центральной Азии- бывших советских республиках - показывает, как продвигаются процессы инклюзии в противоречивых контекстах социально-политических трансформаций, во многом благодаря усилиям родителей, педагогов и общественных ассоциаций (Lapham, Rouse 2013; русскоязычные переводы см.: Журнал исследований социальной политики 11 (4) 2013).

Разработка инструментария для оценивания инклюзивного образования осуществлена британскими исследователями (Бут, Эйнскоу 2007) по трем взаимосвязанным осям: инклюзивная культура, инклюзивная практика и инклюзивная политика. Инклюзивная политика включает две группы показателей-развитие школы для всех и поддержка разнообразия, инклюзивная практика раскрывается через управление процессом обучения и мобилизацию ресурсов. Показатели инклюзивной культуры-это, во-первых, построение школьного сообщества, куда входят характеристики отношений участников образовательного процесса: доброжелательность, взаимопомощь учеников, взаимоуважение учеников и учителей, партнерские отношения между учителями и родителями, вовлеченность в работу школы местных сообществ. Во-вторых, принятие инклюзивных ценностей: ожидание высоких достижений от всех учеников и их равное признание, консенсус всех участников образовательного процесса в отношении ценностей инклюзии, неформальное отношение учеников и учителей друг к другу, стремление учителей преодолевать барьеры обучения и полноценного участия всех учеников в школьной жизни; стремление школы минимизировать все виды дискриминации (там же: 51). Признавая непрерывность 
процесса инклюзии и взаимосвязь всех ее элементов, Тони Бут и Мэл Эйнскоу полагают приоритетом создание инклюзивной культуры (2007: 16-17), поскольку именно она обладает большим потенциалом оказывать влияние на характер и динамику реформ.

В исследованиях образования распространен фокус на организационной культуре (Hubbard et al. 2013; Horenczyk, Tatar 2002). В соответствии с подходом Эдгара Шейна, организационная культура проявляет себя на уровне артефактов (например, архитектурной среде), в провозглашаемых ценностях, определяемых лидером организации, а также на уровне базовых предположений, проявляющихся через установки, устойчивые, но не столь очевидные для стороннего наблюдателя элементы культуры (Schein 2004). Культура привносится лидерами, но в большей степени она является коллективным продуктом, и любое предложение сверху проходит оценку в коллективной среде (Ibid:29). В дальнейшем предложение становится убеждением, а потом коллективным представлением. Но для того чтобы правильно дешифровать поведение членов организации, необходимо обратиться к уровню базовых представлений, которые Шейн предлагает рассматривать как психологические когнитивные защитные механизмы, обеспечивающие функционирование группы (Ibid: 32). И для того, чтобы правильно понять значение артефактов и провозглашенных ценностей, необходимо установить суть культуры на уровне основополагающих, или базовых представлений, понять процесс их принятия членами организации.

Концепция Шейна ранее уже применялась при исследовании инклюзивной образовательной среды (Mickelson 2008; Zollers et al. 1999). В данной работе к исследованию организационной культуры инклюзивной школы вновь привлекаются подходы Шейна, Бута и Эйнскоу. Статья основана на анализе 15 качественных интервью с участниками образовательного процесса, а именно с педагогами, тьютором, родителем в четырех московских и подмосковной школах в 2016-2017 гг. В инструментарии сделан акцент на элементах организационной культуры инклюзивной школы, определяемых вслед за Шейном, Бутом и Эйнскоу. Использовалась целевая выборка интенсивного отбора информационно богатых случаев (Patton 2002: 243-244). Все информанты имеют большой опыт работы с детьми с особенностями развития и детьми с инвалидностью. В трех школах, имеющих наибольший опыт инклюзии, обучаются, в том числе дети с задержкой психического развития, тяжелым нарушением речи, расстройством аутистического спектра, нарушением опорно-двигательного аппарата. В четвертой школе, характеризующейся меньшим опытом инклюзии, среди учащихся с особенностями развития-в основном дети с ДЦП, а также с задержкой развития, с сахарном диабетом. Интервью с элементами этнографического наблюдения проводилось в школах. Кроме того, были использованы данные, полученные в интервью с детьми $(\mathrm{N}=4)$ и родителями детей с инвалидностью и без инвалидности $(\mathrm{N}=11)$ в Москве, 
Улан-Удэ и Самаре в рамках проекта «Отношение общества к детям с ограниченными возможностями здоровья и детям-инвалидам», выполненного НИУ ВШЭ в 2016 г. по заказу Фонда поддержки детей, находящихся в трудной жизненной ситуации (Фонд поддержки детей 2017).

\section{Визуальные артефакты инклюзии}

Визуальные артефакты- это так называемый поверхностный, внешний уровень организационной культуры. Сюда можно отнести, в том числе, архитектурную среду школ, их оснащенность техническими средствами, сенсорными комнатами, результаты творчества детей. На этажах, в классах и кабинетах сотрудников представлены результаты творчества и достижения учащихся, награды, грамоты, картины, нарисованные и вышитые детьми, в том числе с инвалидностью. Артефакты вплетены в повседневность учеников и учителей школы, находясь на виду у всего коллектива учебного заведения. Во время интервью информанты показывали рисунки, выполненные учениками с аутизмом, обращая внимание на их успехи в творчестве. Можно предположить, что наблюдаемые артефакты инклюзии могут побуждать учеников и учителей к соблюдению транслируемых школой норм поведения, связанных с осознанием того, что дети с особенностями наравне со всеми вовлечены в повседневную жизнь.

В ряде школ в классах, кроме учеников и учителей, по наблюдениям автора, находились и родители учеников, ведь в школах отсутствует необходимый штат сотрудников- не только тьюторов, которые помогают в учебном процессе, но и ассистентов, поскольку помощь бывает необходима и за пределами учебного процесса. Как утверждают информанты, в школах созданы специальные условия для учеников с инвалидностью и OBЗ: помещения доступны для использования всеми учениками, включая и детей с инвалидностью. Однако специальных технических средств недостаточно, например, для электронного образования. В интервью отмечается, что в одном здании школы есть адаптированный лифт, а другой корпус, напротив, не оборудован подъемными устройствами, и в случае необходимости приходится прибегать к помощи тьюторов или родителей. Наличие доступной среды позволило бы ученикам быть более мобильными и независимыми:

Я хочу быть без тьютора. Чтобы быть уже самостоятельной. И когда уже будет подъемник, не быть уже ограниченной в движении... А когда у нас такой вот мини просмотр, то мы, бывает, целую перемену можем разбирать ошибки, чтобы было понятнее, чтобы потом нормально рисовать. А тьютор, она меня часто торопит, и я из-за этого дергаюсь. Знаю, что она сейчас начнет собирать за меня портфель, папку класть (Интервью 18. Ребенок с инвалидностью, обучающийся в инклюзивной школе, девочка. Москва). 
Данный уровень культуры заметен для участников образовательного процесса, для сторонних наблюдателей, однако он может показывать лишь поверхностную картину того, что происходит в самих школах. Поэтому следует обратиться к ценностному уровню культуры, раскрывающемуся через декларируемые принципы и нормы, которых придерживаются сотрудники, ученики школы. Несмотря на большой акцент на равенстве, в ценностном ядре инклюзивной культуры находится еще и разнообразие. Это одно из важнейших условий инклюзии-все разные, но при этом равные.

\section{Ценность различий}

Позиция в отношении учеников с ОВ3 «не навязывать ярлыки» приводит к определенному пониманию концепции инклюзии, в которой разнообразие выступает ценным ресурсом: «B каждом есть то, чего нет y другого» (Интервью 2. Тьютор, ж., около 40 лет. Москва). При этом задачей школы, по мнению информанта, является «обеспечение индивидуального маршрута, образовательного, ребенка ... чтобы у него было нормальное детство» (Интервью 6. Учитель начальной школы, м., около 35 лет. Москва). Разделяемые участниками идеи инклюзии имеют непосредственное отношение к ценностному аспекту организационной культуры инклюзивной школы. Педагоги понимают под идеей инклюзии социальный, а не только образовательный процесс. Один из информантов отмечает, что идея инклюзии предполагает принадлежность к обществу, где есть возможность быть услышанным, что у каждого человека есть свои особые потребности. Высказывается также позиция, что «инклюзия- это соииальная солидарность» (Интервью 4. Учитель-дефектолог, ж., около 50 лет. Москва). Это означает, что все участники инклюзивного процесса едины, но индивидуальны, и отличаясь друг от друга, члены группы в то же время дополняют друг друга, что созвучно идеям органической солидарности (Дюркгейм 1991).

Школьные педагоги делают акцент на том, что общество должно быть готово не только принимать людей с особыми потребностями, но и подстраиваться под них. Именно в этом проявляется социальный подход к определению инвалидности (Тарасенко 2004: 9), с позиции которого не инвалидность и ограниченные возможности здоровья являются ограничениями - барьеры создаются окружающей физической и социальной средой. По мнению опрошенных, инклюзивное образование должно начинаться не с методики образования, а с культуры принятия другого. И хотя родители иногда принимают решение перевести ребенка в другую школу по причине разногласий «с классным руководителем, с иелями и задачами» (Интервью 4. Учитель-дефектолог, ж., около 50 лет. Москва), все же, как отмечают почти все информанты, идеи инклюзии в широком ее понимании (как включение в социум) разделяются всеми участниками образовательного процесса. 
Какими же способами распространяются ценности инклюзии? Вовлечение учеников с OB3 во внеклассные активности выступает важным механизмом развития организационной культуры инклюзивной школы. Именно посредством внеурочных коллективных мероприятий, дети сплачиваются друг с другом, работая в команде. В школах проходят родительские собрания, посвященные данной тематике. Для новых сотрудников, как указывают педагоги, в неформальной обстановке проводятся специальные семинары по инклюзии.

В ряде интервью отмечалось, что для учеников с особенностями развития при включении в новую школу важна практика адаптации как составляющая организационной культуры инклюзивной школы. По словам педагогов одной из школ, новичкам - ученикам и учителям- помогает адаптироваться психолог. При этом, различия между детьми не акцентируются: «Зачем выставлять напоказ то, что ребенок нехотел бы? Они очень за то, чтобы быть такими, как все» (Интервью 2. Тьютор, ж., около 40 лет. Москва).

Согласно концепции Шейна, культура, характеризующаяся устойчивостью, привносится лидерами, которые сообщают свои ценности и представления группе (Шейн, 2002:22). Директор школы воспринимается как глава организации, который «погружен» в процесс, осознает значимость образовательной деятельности школы и влияет на путь ее развития. Отметим, что мы не брали интервью с директорами школ, поэтому роль лидера можем представить только по нарративам педагогов и родителей. Учителя указывают, что именно благодаря активности руководителя, поддержке выдвинутых инициатив, происходит обмен опытом с другими внешними школе специалистами:

Невозможно научить ценить другую личность, если ты чувствуешь, что не ценят тебя. ...Да, директор понимает, как это важно, что в ее команде... каждый человек индивидуален, ценен, и мы чувствуем от нее огромную поддержку и у нас есть желание давать что-то в ответ (Интервью 3. Специалист организации дополнительного образования, ж., около 25 лет. Москва).

Некоторые информанты подчеркивали, что работают в школе только благодаря руководителю учебного заведения, который морально поддерживает учителей, не препятствует инновациям, связанными с развитием инклюзии на уровне разделяемых ценностей в школе:

...я так думаю, что если бы у меня не было такой серьезной поддержки директора, то я бы, наверное, здесь уже и не работала, и не было бы вообще всего этого... (Интервью 13. Социальный педагог, ж., около 35 лет. Подмосковье).

Декларируемая выше роль директора школы в формировании направления развития инклюзии, раскрывает ценностный уровень культуры, который осознается и проговаривается участниками образовательного 
процесса, конституируется изнутри, на уровне базовых предположений, разделяемых и зачастую не осознаваемых сотрудниками.

\section{Уровень базовых предположений: отношения участников в инклюзивной школе}

Рассмотрение глубинного уровня организационной культуры затрагивает изучение установок участников образовательного процесса по отношению к детям с особенностями развития. Почти все информанты указывают на особую дружественную атмосферу. Эта атмосфера характеризуется тем, что «происходит принятие другого человека, система иенностей внутренняя» (Интервью 3. Специалист организации дополнительного образования, ж., около 25 лет. Москва). При этом, по мнению некоторых опрошенных, конфликты редки, но если и случаются, то их инициируют те ученики, которые обучаются в школе не с начальных классов и ранее становились объектами травли из-за своих особенностей:

Они приходят сюда, поскольку из тех школ их погнали, или они сами уже в неврозах все <... Они приходят сюда, успокаиваются и, видя, что никто их не гнобит, видят детей слабых, доверчивых, с особенностями и начинают те порядки приносить в школу (Интервью 5. Родитель ребенка с инвалидностью, педагог-организатор, ж., около 50 лет. Москва).

Информант объясняет такое поведение учеников не только их ценностями, которые не соответствуют культуре новой школы. В нарративе представлены также и различающиеся паттерны поведения учеников из разных школ («начинают приносить», «гнобить»), эмоциональная работа («неврозы», «успокаиваются»), отношения власти («их погнали», «никто не гнобит», «слабые, доверчивые»). Только со временем пришедшим ученикам получается включиться в образовательный процесс и принять сложившуюся культуру.

Информанты рассказывали нам об активной позиции учеников, защищающих своих сверстников с особенностями развития от оскорбительных высказываний одноклассников:

И даже у нас такой случай был < ..> спрашивают дети: «А почему вы на физкультуру не ходите?». Другой ребенок говорит: «Да они инвалиды, они не ходят на физкультуру». И тут девочка встает из нашего класса, руки в боки: «Это не инвалиды, это дети с особенностями в развитии, не называй их так». Дети сами регулируют эти отношения, если им не мешать и не навязывать свое мнение (Интервью 20. Родитель ребенка с инвалидностью, обучающегося в инклюзивной школе, ж. Москва).

Это может говорить о существовании определенной культуры внутри учебного заведения, которая регулирует отношения на глубинном уровне. Информанты делают акцент на том, что в процессе реализации инклюзии 
формируется среда, которая учит «понимать и принимать тех людей, которые рядом с нами» (Интервью 3. Специалист организации дополнительного образования, ж., около 25 лет. Москва). Учителя указывают на то, что для школы главное- не рейтинг, не академические успехи, а гуманистические ценности, позволяющие дать такое образование, которое поможет «интегрироваться в сочиум, сочииализироваться в том смысле, чтобы получить свое собственное место под солнцем, которое будет подходить ему, нравиться ему» (Интервью 6. Учитель начальной школы, м., около 35 лет. Москва). Цель инклюзии, по словам информантов, заключается в социальной интеграции, включении детей с инвалидностью в общество, чтобы человек в результате испытывал удовлетворенность, был счастливым.

Педагоги из двух московских школ делают акцент на персонифицированных отношениях между участниками, при этом негативной стороной, по их мнению, выступает слишком уж короткая дистанция между учеником и педагогом,

потому что дети настолько привыкают, что с ними каждый учитель как мама, что входит в их особенности положения, что к 11-му классу они начинают уже наглеть. Вот это вот тоже, я считаю, что плохо. Нельзя их так сильно любить (Интервью 1. Методист-координатор инклюзивного образования, ж., около 40 лет. Москва).

Лейтмотивы тесной дистанции, нарушения и очерчивания границ звучат и в интервью с родителями. На данный момент некоторым приходится выполнять роль ассистента, поэтому они встраиваются в учебный процесс наравне с другими участниками:

Я в их классе уже как свой одноклассник, руководитель. Завучу что-то надо, она у меня спросит, кто откуда. Даже детей из первого класса уже знаю. Иногда Маша говорит, «не заходи на перемене». Ей хочется пообщаться. Если бы был какой-то посторонний человек, не родственник, там уже другое отношение было бы (Интервью 16. Родитель ребенка с инвалидностью, обучающегося в инклюзивной школе, ж.. Улан-Удэ).

Рассказчица обращает наше внимание на то, что включение родителей в образовательный процесс, с одной стороны, наделяет их определенным статусом с довольно высоким уровнем социального капитала, и в то же время ведет к чересчур тесному детско-родительскому взаимодействию в пространстве школы, проникновению родителя в «детский мир» сверстников, что является нарушением границ с точки зрения ребенка. Но при этом существует возможность договариваться: ребенок просит мать не заходить на перемене, то есть выдвигает свои правила и настаивает на своих границах.

Принятие среди других учеников детей с особенностями не означает формирование тесного взаимодействия и дружбы. Несмотря на хорошее отношение, практику помощи со стороны других детей, некоторые ученики с инвалидностью чаще общаются и дружат между собой, «[n]отому что они 
такие же, как я. Понимающие меня, и я их понимаю» (Интервью 19. Ребенок с инвалидностью, обучающийся в инклюзивной школе, девочка, 14 лет. УланУдэ). Формируется ли дистанция между самими учениками с инвалидностью или это результат проявления более комплексных установок?

В случае, если другие ученики не общаются с детьми с особенностями, по мнению девочки с инвалидностью, то это происходит не по причине состояния здоровья, а потому что «не нашли мы с ними общий язык», так как, «видимо, по характеру разные» (Интервью 17. Ребенок с инвалидностью, обучается в инклюзивной школе, девочка, 17 лет. Улан-Удэ). По материалам канадского исследования, дружба между учениками с инвалидностью и остальными детьми в инклюзивных школах способствует наращиванию культурного капитала, который содействует социальному признанию учеников (Банч, Валео 2008).

Но организационная культура школ формируется не в вакууме; ценности инклюзии прививаются не только в школе, но и в семье, и разнообразных социальных и культурных контекстах. Отметим, что по данным Всероссийского опроса, дети с проблемами умственного развития, дети с синдромом Дауна, незрячие, неслышащие и дети с особенностями психического развития должны учиться в специализированных школах - с этим согласилось абсолютное большинство опрошенных респондентов (Фонд поддержки детей 2017). Инклюзия как принцип организации образования и социальной жизни в целом не стала разделяемой ценностью в обществе.

Между принципами инклюзивной политики на макроуровне и их реализацией на микроуровне, то есть в самих школах, прослеживается двунаправленная связь. Прежде всего, она выражается через воплощение в реальность положений нормативно-правовых актов, включая государственную программу «Доступная среда», которая предписывает сделать школьные здания и классы доступными для учеников с физической инвалидностью. Выполнение требований законов, образовательных стандартов достигается за счет универсальных решений, которые направлены на изменение архитектурной и образовательной среды в каждой общеобразовательной школе. Создание учебных помещений, адаптированных учебных материалов, обеспечение участия всех учеников в обучении и школьной жизни, возможность профессиональной переподготовки учителей в сфере инклюзивного образования, все это- универсальный тренд. На микроуровне в учебных заведениях реализация принципов инклюзивной политики, в том числе темпы ее претворения в жизнь, взаимоувязана не только с формальным выполнением предписанных требований, с обеспечением надлежащей архитектурной среды школ, их оснащенностью техническими средствами, но и с изменением ценностного аспекта культуры. Поэтому видимые изменения в школьной политике в сторону инклюзии могут выглядеть схожим образом в разных школах. В то время как глубокие изменения, затрагивающие аспект отношений, 
установок, поведения, в каждом учебном заведении будут происходить по собственной траектории, с разными темпами, и зависеть от того, какой у школы уже есть опыт, наработки в сфере обучения детей с инвалидностью, от заинтересованности руководителей и коллектива школы. Глубинные уровни школьной культуры будут оказывать влияние на темпы и качество проведения реформ в направлении инклюзии.

\section{Заключение}

Поворот к инклюзии - это мировая практика. В России происходят серьезные изменения на уровне стратегических решений и в практике работы организаций. Образовательные учреждения сталкиваются с новыми вызовами, проводя организационное переустройство и развивая новые подходы к обучению и воспитанию детей. Трансформируется организационная культура школ и других образовательных учреждений. Однако новая среда формируется не только как результат проводимых сверху реформ. Изменения в организационной культуре происходят благодаря тому, что ценности, которые лидер транслирует другим участникам образовательного процесса, воплощаются в наблюдаемых артефактах, практиках взаимодействия и убеждениях. Эти перемены могут быть успешными только в случае, если ценности и принципы инклюзивного образования разделяются сотрудниками и учениками школы, если сформированы установки на инклюзию на глубинном уровне.

Организационные ценности, нормы и установки, складываясь в процессе повседневного взаимодействия, и действия руководителя и всего коллектива, могут способствовать, а могут выступать барьером на пути преобразований. На инклюзию влияют и предпринимаемые инициативы «снизу», через паттерны поведения, провозглашаемые ценности и визуальные элементы поверхностного уровня культуры. Разделяемые ценности связаны с принятием различий, индивидуальности каждого ученика в контексте солидарности органического типа, сплоченной и поддерживающей среды. Инклюзивный характер образовательных учреждений проявляется и в том, что среда, окружающая детей с инвалидностью в учебном заведении, меняется с целью их успешной интеграции в общественную жизнь. Инклюзия - это в первую очередь социальный процесс, предполагающий не только достижения в учебе, но и формирование коммуникативных навыков, которые являются залогом успешной социализации любого ребенка. Вовлечение школьников с ОВ3 во внеклассные активности, адаптация учителей и учеников, проведение мероприятий для родителей по теме инклюзии и другие действия составляют комплекс стратегий развития инклюзии на всех уровнях.

Полученные результаты важны не только в инклюзии детей с инвалидностью и ОВ3, но применимы к детям мигрантов, детям-сиротам- 
к любым учащимся, поскольку особенности есть у каждого ребенка, и инклюзивная среда максимально отвечает потребностям в росте и развитии на принципах гуманизма и сплоченности отдельных детей, классов, педагогов и школы как организации. Инклюзия может воплощаться в отдельно взятой школе, но что ожидает ее учеников, стоит им выйти за пределы учебного заведения? Очевидно, речь должна идти об изменении ценностной структуры и базовых установок во всем обществе. Инклюзивное развитие школ этому может способствовать.

\section{Выражение признательности}

Выражаю благодарность Е.Р. Ярской-Смирновой (д.с.н., профессору НИУ ВШЭ) за помощь в работе над статьей и предоставление доступа к архиву расшифровок интервью, собранных в рамках проекта «Отношение общества к детям с ограниченными возможностями здоровья и детям-инвалидам» Фонда поддержки детей, находящихся в трудной жизненной ситуации.

В работе использованы результаты проекта «Мобилизация и повышение качества человеческого капитала среднего класса и уязвимых групп населения», выполненного в рамках Программы фундаментальных исследований НИУ ВШЭ в 2019 г.

\section{Список источников}

Банч Г., Валео Э. (2008) Влияние специального и инклюзивного образования на установки сверстников: практическое и теоретическое исследование. Журнал исследований соииальной политики, 6 (1): 23-52.

Бут Т., Эйнскоу М. (2007) Показатели инклюзии. Практическое пособие. М.: Перспектива.

Дюркгейм Э. (1991) О разделении общественного труда. Метод соииологии. Перевод с французского А.Б. Гофмана. М.: Наука.

Здрагат С.Г. (2017) Умови реалізації соціальної технології евалюації інклюзивної освіти. Науково-теоретичний альманах «Грані», 20 (4): 10-16.

КОУЖ (2016) Комплексное наблюдение условий жизни населения. Доступно по ссылке: www.gks.ru/free_doc/new_site/KOUZ16/index.html (дата обращения: 4 апреля 2019).

Приказ Министерства образования и науки РФ (2014) Об утверждении федерального государственного образовательного стандарта начального общего образования обучающихся с ограниченными возможностями здоровья № 1598 от 19.12.2014 г.

РИА Новости (2017) Васильева: инклюзивное образование могут обеспечить $21 \%$ российских школ. Доступно по ссылке: https://sn.ria.ru/20170629/1497534823.html (дата обращения: 30 апреля 2019).

Тарасенко Е. (2004) Социальная политика в области инвалидности: кросскультурный анализ и поиск оптимальной концепции для России. Журнал исследований соииальной политики, 2 (1): 7-28. 
Федеральный закон (2012а) О ратификащии Конвенции о правах инвалидов № 46-Ф3 от 3.05.2012 г.

Федеральный закон (2012b) Об образовании в Российской Федерации № 273-Ф3 от 29.12.2012 г.

Фонд поддержки детей (2017) Отношение общества к детям с ограниченными возможностями здоровья и детям-инвалидам. М.: Фонд поддержки детей, находящихся в трудной жизненной ситуации. Доступно по ссылке: https://www.hse.ru/ mirror/pubs/share/206979080 (дата обращения: 15 апреля 2019).

Ярская-Смирнова Е., Присяжнюк Д., Ярская-Смирнова В., Баранова А. (2015) Социальная инклюзия и сплоченность в школьном образовании: политика и практика. Н.Е. Покровский, М.А. Козлова (ред.) Социально-культурные практики сплоченности в современных обществах. М.: Университетская книга: 250-283.

Dyson L. (2010) Unanticipated Effects of Children with Learning Disabilities on Their Families. Learning Disability Quarterly, 33 (1): 43-55.

Horenczyk G., Tatar M. (2002) Teachers' Attitudes toward Multiculturalism and Their Perceptions of the School Organizational Culture. Teaching and Teacher Education, 18 (4):435-445.

Hubbard L. A., Stein M. K., Mehan H. (2013) Reform as learning: School Reform, Organizational Culture, and Community Politics in San Diego. New York: Routledge.

Lapham K., Rouse M. (2013) Learning to See Invisible Children: Inclusion of Children with Disabilities in Central Asia. Budapest: Central European University Press.

Mickelson K. A. (2008) A Case Study of Co-Teaching Between a Regular Education Teacher and a Special Education Teacher in an Elementary School. Doctoral dissertation. Wichita: Wichita State University.

Patton M. (2002) Qualitative Research and Evaluation Methods. $3^{\text {rd }}$ ed. Beverly Hills: Sage.

Pivik J., McComas J., Laflamme M. (2002) Barriers and Facilitators to Inclusive Education. Exceptional Children, 69 (1):97-107.

Resch J.A., Mireles G., Benz M.R., Grenwelge C., Peterson R., Zhang D. (2010) Giving Parents a Voice: A Qualitative Study of the Challenges Experienced by Parents of Children with Disabilities. Rehabilitation Psychology, 55 (2): 139-150.

Ruijs N. M., Peetsma T. T.D. (2009) Effects of Inclusion on Students with and without Special Educational Needs Reviewed. Educational Research Review, 4 (2): 67-79.

Schein E. H. (2004) Organizational Culture and Leadership (Jossey-Bass Business \& Management Series). San Francisco: Jossey Bass Incorporated.

Zollers N. J., Ramanathan A.K., Yu M. (1999) The Relationship Between School Culture and Inclusion: How an Inclusive Culture Supports Inclusive Education. International Journal of Qualitative Studies in Education, 12 (2): 157-174. 
Aleksandra Goriainova

\title{
'A PLACE UNDER The SUN': LEVELS OF DEVELOPMENT IN SCHOOL INCLUSION
}

\begin{abstract}
A key priority of social policy in developed countries is the active involvement of people with disabilities in society, including education. The transformation of state policy in Russia along these lines has been accompanied by changes in the legal system. In turn, these reforms are gradually contributing to overcoming prejudices in society towards people with disabilities. In recent years, there have been significant changes in the field of educational policy of Russia towards increased inclusion. The formation of inclusive organizational cultures in schools is no less an important condition for providing an accessible environment, however, than the removal of architectural and technological barriers. In this article, an analysis of the main valuesymbolic characteristics of school inclusion is provided, based on qualitative interviews with teachers, pupils and parents. This research was conducted on the basis of Edgar Schein's concept of organizational culture that views inclusion on three levels: artifacts, espoused values, and basic assumptions. It is shown that changes in schools occur due to the fact that the values that the leader translates to other participants of the educational process are embodied in observed artifacts, practices of interaction and unspoken beliefs. Organizational values, norms and attitudes, emerging in the process of dayto-day interaction, can contribute to or act as a barrier on the path of transformation. The culture of an organization is also influenced by the initiatives taken 'from below' through patterns of behavior, proclaimed values and visual elements on the surface level of culture. Shared values are associated with the acceptance of differences, the individuality of each pupil in the context of building a supportive environment.
\end{abstract}

Key words: inclusive education, students with disabilities, organizational culture, social inclusion, qualitative methods

DOI: $10.17323 / 727-0634-2019-17-4-555-570$

\section{References}

Booth T., Ainscow M. (2007) Pokazateli inklyuzii [Inclusion Indicators]. Prakticheskoe posobie [A Practical Guide]. Moscow: Perspektiva.

Bunch G., Valeo A. (2008) Vliyanie special'nogo i inklyuzivnogo obrazovaniya na ustanovki sverstnikov: prakticheskoe i teoreticheskoe issledovanie [The Impact of Special Education and Inclusive Education Structures on the Attitudes of Typical Peers: A Practical and

Aleksandra Goriainova- Doctoral Student, Faculty of Social Sciences; Research Assistant, Centre for Studies of Income and Living Standards, Institute for Social Policy, National Research University Higher School of Economics, Moscow, Russian Federation. Email: agoryajnova@hse.ru 
Theoretical Exploration]. Zhurnal issledovanij social'noj politiki [The Journal of Social Policy Studies], 6 (1): 23-52.

Children Support Fund (2017) Otnoshenie obshchestva k detyam s ogranichennymi vozmozhnostyami zdorov'ya i detyam-invalidam [Society's Attitude to Children with Limited Health Opportunities and Children with Disabilities]. Moscow: Fond podderzhki detej, nahodyashchihsya v trudnoj zhiznennoj situacii. Available at: https://fond-detyam.ru/upload/iblock/90f/ Отношение $\% 20$ общества $\% 20$ к\% 20 детя $\% 20$ с $\% 20$ ограниченными \% 20 возможностями\%20здоровья\%20и\%20детям-инвалидам.pdf (accessed 15 April 2019).

CMLC (2016) Kompleksnoe nablyudenie uslovij zhizni naseleniya [Comprehensive Monitoring of Living Conditions]. Available at: www.gks.ru/free_doc/new_site/KOUZ16/index.html (accessed 4 April 2019).

Durkheim É. (1991) O razdelenii obshchestvennogo truda. Metod sociologii [On the Division of Social Labour. The Method of Sociology]. Translation from French by A. B. Gofman. Moscow: Nauka.

Dyson L. (2010) Unanticipated Effects of Children with Learning Disabilities on their Families. Learning Disability Quarterly, 33 (1):43-55.

Federal Law (2012a) O ratifikacii Konvencii o pravah invalidov [On the Ratification of the Convention on the Rights of Persons with Disabilities] № 46-FZ from 3.05.2012.

Federal Law (2012b) Ob obrazovanii v Rossijskoj Federacii [On Education in the Russian Federation] № 273-FZ from 29.12.2012.

Horenczyk G., Tatar M. (2002) Teachers' Attitudes toward Multiculturalism and their Perceptions of the School Organizational Culture. Teaching and Teacher Education, 18 (4): 435-445.

Hubbard L. A., Stein M. K., Mehan H. (2013) Reform as Learning: School Reform, Organizational Culture, and Community Politics in San Diego. New York: Routledge.

Iarskaia-Smirnova E., Prisyazhnyuk D., Iarskaia-Smirnova V., Baranova A. (2015) Social'naya inklyuziya i splochennost' v shkol'nom obrazovanii: politika i praktika [Social Inclusion and Cohesion in School Education: Policy and Practice]. In: N.E. Pokrovskij, M.A. Kozlova (eds.) Social'no-kul'turnye praktiki splochennosti v sovremennyh obshchestvah [Social and Cultural Practices of Cohesion in Modern Societies]. Moscow: Universitetskaya kniga:250-283.

Lapham K., Rouse M. (2013) Learning to See Invisible Children: Inclusion of Children with Disabilities in Central Asia. Budapest: Central European University Press.

Mickelson K. A. (2008) A Case Study of Co-Teaching Between a Regular Education Teacher and a Special Education Teacher in an Elementary School. Doctoral dissertation. Wichita: Wichita State University.

Order of the Ministry of Education and Science of the Russian Federation (2014) Ob utverzhdenii federal'nogo gosudarstvennogo obrazovatel'nogo standarta nachal'nogo obshchego obrazovaniya obuchayushchihsya s ogranichennymi vozmozhnostyami zdorov'ya [On the Approval of the Federal State Educational Standard of Primary General Education of Students with Disabilities] № 1598 from 19.12.2014.

Patton M. (2002) Qualitative Research and Evaluation Methods. $3^{\text {rd }}$ ed. Beverly Hills: Sage.

Pivik J., McComas J., Laflamme M. (2002) Barriers and Facilitators to Inclusive Education. Exceptional Children, 69 (1): 97-107. 
Resch J.A., Mireles G., Benz M.R., Grenwelge C., Peterson R., Zhang D. (2010) Giving Parents a Voice: A Qualitative Study of the Challenges Experienced by Parents of Children with Disabilities. Rehabilitation Psychology, 55 (2): 139-150.

RIA Novosti (2017) Vasil'eva: inklyuzivnoe obrazovanie mogut obespechit' 21\% rossijskih shkol. [Vasilyeva: Inclusive Education Can Be Provided by $21 \%$ of Russian Schools]. Available at: https://sn.ria.ru/20170629/1497534823.html (accessed 30 April 2019).

Ruijs N. M., Peetsma T. T.D. (2009) Effects of Inclusion on Students with and without Special Educational Needs Reviewed. Educational Research Review, 4 (2): 67-79.

Schein E.H. (2004) Organizational Culture and Leadership (Jossey-Bass Business \& Management Series). San Francisco: Jossey Bass Incorporated.

Tarasenko E. (2004) Social'naya politika v oblasti invalidnosti: krosskul'turnyj analiz i poisk optimal'noj koncepcii dlya Rossii [Social Policy in the Field of Disability: CrossCultural Analysis and Search for the Optimal Concept for Russia]. Zhurnal issledovanij social'noj politiki [The Journal of Social Policy Studies], 2 (1): 7-28.

Zdrahat S.H. (2017) Umovy realizatsiyi sotsialnoyi tekhnolohiyi evalyuatsiyi inklyuzyvnoyi osvityv [Conditions for the Realization of the Social Technology of Inclusive Education's Evaluation]. Naukovo-teoretichnij al'manah 'Grani' [Scientific and Theoretical Almanac 'Grani'], 20 (4): $10-16$.

Zollers N.J., Ramanathan A.K., Yu M. (1999) The Relationship Between School Culture and Inclusion: How an Inclusive Culture Supports Inclusive Education. International Journal of Qualitative Studies in Education, 12 (2): 157-174. 